\title{
La negociación, piedra angular de las investigaciones
}

\section{Negotiation, cornerstone of qualitative research}

\author{
Miguel Ángel Santos Guerra ${ }^{1}$ \\ arrebol@uma.es \\ Lourdes De la Rosa Moreno \\ Idelarosa@uma.es \\ Universidad de Málaga, España
}

\section{Resumen:}

El artículo consta de dos partes complementarias. Una de ellas trata de explicar la importancia de los procesos de negociación en la realización de investigaciones y evaluaciones. Importancia que se basa en cinco razones: ética de los procesos de producción y aplicación del conocimiento, rigor de las indagaciones, eficacia de los hallazgos para la mejora, estrategia para mantener contextos en que se pueda investigar y aprendizaje de los y las participantes. Se plantean las distintas fases de la negociación: inicial, de proceso y de informes, con especial atención a esta última. De ella se estudian las exigencias, los tipos, las características y los procedimientos de actuación.

La segunda parte muestra, a modo de ejemplo, un caso concreto de negociación de una investigación cualitativa sobre la participación de familias inmigrantes en la escuela, con sus diversas fases, exigencias y virtualidades.

Se cierra el artículo con algunas consideraciones finales y con la correspondiente bibliografía.

\section{Palabras clave:}

Educación; investigación; evaluación; ética; rigor; negociación; mejora; aprendizaje.

\section{Abstract :}

The first section of this paper focuses on the importance of negotiation processes related to research and evaluation. This importance is based on five issues: ethics in production processes, knowledge scope, rigorous inquiry, efficiency of development-oriented findings, and strategy to maintain contexts in which research and participant learning can take place. The different phases of the negotiation process are also presented: initial, processing and reporting, the last one of special importance. The requirements, types, characteristics and operation processes of the reporting phase are discussed. The second section of this paper provides in the form of an example a specific case of negotiation from a qualitative investigation about immigrant families' participation at school. Its different phases, demands and virtualities are discussed. The paper finished with some final considerations and references.

\section{Key words:}

Education; qualitative research; evaluation; research ethics; validity; negotiation; improvement; learning.

\section{Dirección para correspondencia (correspondence address):}

Miguel Ángel Santos Guerra. Departamento de Didáctica y Organización Escolar. Facultad de Ciencias de la Educación. Universidad de Málaga. Campus de Teatinos, s/n. 29071 Málaga (España) 


\begin{abstract}
Résumé :
L'article se compose de deux parties. La première essaie d'expliquer l'importance du processus de négociation dans le développement des recherches et des évaluations. L'importance de ce processus repose sur cinq principes : I'éthique des processus de production et d'application de la connaissance, la rigueur des enquêtes, l'efficacité des découvertes pour son amélioration, la stratégie pour maintenir les contextes de recherche, et l'apprentissage des participants. Les phases de la négociation sont les suivante : initiale, de processus et de rapports, cette dernière méritant une attention plus spéciale. À travers elle sont étudiées les exigences, les types, les caractéristiques et les procédures d'actions. La deuxième partie aborde, par exemple, un cas concret de négociation menée dans une recherche qualitative sur la participation des familles immigrantes à l'école, avec ses diverses phases, ses exigences et ses virtualités.

L'article s'achève avec quelques considérations finales et avec la bibliographie correspondante.
\end{abstract}

\title{
Mots clés:
}

Éducation; recherche; évaluation; éthique; rigueur; négociation; amélioration; apprentissage.

Fecha de recepción: 26-7-2016

Fecha de aceptación: 7-10-2016

\section{Introducción}

Llevamos muchos años insistiendo en esta cuestión. Muchos años. Y vemos con preocupación que no hay un cuerpo teórico de reflexión sistemática sobre ella. Nos referimos a la necesidad de la negociación de los proyectos de investigación o de evaluación con la comunidad en la que se realizan. Negociación de la iniciativa, de la finalidad, de las condiciones, del proceso, de los informes...

La dirección de tesis doctorales, la participación en investigaciones, la realización de evaluaciones de diferente naturaleza (de sistemas, de programas, de instituciones, de experiencias...), la presencia en tribunales de tesis y de trabajos de Fin de Grado y de Fin de Máster, la presencia en comisiones evaluadoras de proyectos..., nos ha hecho buscar insistentemente lo relacionado con esta exigencia capital. Y hemos visto que, en muchos casos, no hay ni rastro de ella. Cuando existe se pasa de puntillas sin explicitar los pasos del proceso negociador y sin dejar constancia de los efectos que ha producido en la investigación (o evaluación), en los informes o en las medidas posteriores.

Hablamos de investigaciones y de evaluaciones. No toda investigación es una evaluación aunque toda evaluación es una investigación. Cada una de las modalidades de exploración tiene sus peculiaridades 
y sus exigencias. Pero en las dos se hace necesaria, a nuestro juicio, la presencia de la negociación. Téngase en cuenta que, cuando en adelante hablemos de investigación, nos estaremos refiriendo también a la evaluación. Advertimos, no obstante, de que no se trata de fenómenos idénticos y de que en cada uno de ellos la negociación tendría variaciones diferenciadoras. Lo sustancial, sirve para ambos.

Hablamos de una necesidad fundamental porque tiene que ver con cinco dimensiones importantes de la construcción y de la aplicación del conocimiento. En primer lugar, con la ética. Negociar la investigación nos sitúa en una esfera de dignidad y de respeto sin las cuales habría que cuestionar cualquier proceso de búsqueda. Hemos visto muchas investigaciones que se han construido sobre cimientos de falsedad y de engaño. Solo se ha tenido en cuenta el interés de quien hacía el proyecto con el fin de terminar una tesis y obtener un título, escribir un artículo o publicar un libro. Sin claridad en los propósitos, sin propuesta de condiciones, sin reglas del juego, sin normas de procedimiento, sin devolución de informes, sin discusión de los mismos... Los sujetos de la investigación actúan, en estos casos, como "conejillos de Indias" al servicio de los intereses de quien investiga. Hemos visto incluso el incumplimiento de promesas de entrega de informes, a pesar de figurar por escrito en la petición de autorización para entrar en el campo a recoger información.

En segundo lugar, tiene que ver con el rigor de la investigación. No se obtiene la misma información cuando quien la ofrece goza de libertad y de cercanía emocional que cuando el informante está atenazado por los miedos, por la desconfianza o por la falta de transparencia. Pondremos un ejemplo más que evidente: si alguien nos observa en el aula para realizar una investigación no nos comportamos de la misma manera que si controlamos el informe, si podemos emitir opinión sobre el mismo, que si nos observan de forma inapelable. En el segundo caso es más fácil que se produzca la artificialización del comportamiento. No es igual que se pueda opinar sobre el informe y aclarar que se ha captado mal un pensamiento emitido en una entrevista o que se ha interpretado mal un comportamiento.

En tercer lugar, tiene que ver con la eficacia del conocimiento. ¿Para qué se investiga? ¿Al servicio de quién? ¿Solo de quien investiga? ¿O también de quienes participan en la investigación como informantes o sujetos? A través de la negociación se conoce la finalidad, se discuten los resultados y se buscan caminos para la aplicación de las conclusiones 
a la realidad. La negociación puede plantear un importante vínculo con la mejora.

En cuarto lugar tiene relación con la estrategia que se establece para seguir explorado o investigando en ese contexto. Hay investigadoras e investigadores que, después de pasar por el escenario de investigación, dejan ese lugar destruido durante varias generaciones para que se vuelva a hacer otra investigación. Si se negocia, si se establece un diálogo fecundo sobre el proceso y sobre los resultados es más fácil que se vuelvan a poner en marcha en ese contexto esos procesos de indagación.

En quinto lugar tiene que ver con el aprendizaje. Porque en el diálogo entre sujetos e investigadores, en ese intercambio respetuoso y abierto, todos podemos aprender. Podemos reconocer errores, contrastar perspectivas, rectificar enfoques, asumir sugerencias... La negociación convierte el proceso de investigación en una estrategia de aprendizaje. No solo por los resultados obtenidos sino por lo que se descubre.

La palabra negociación, utilizada para denominar los procesos a los que nos estamos refiriendo, necesita algunas precisiones. En primer lugar porque se trata más de un diálogo que de una transacción. Tomo la acepción que el término tiene en el derecho internacional: negociar es examinar en común. En segundo lugar porque estamos habituados a entender la negociación como un proceso en el que unos ganan y otros pierden. En este caso, una buena negociación hará que todos salgan ganando.

Si los de la otra parte ven la negociación como un asunto de ganar/perder, estarán resueltos a derrotarlo. Tal vez se guíen por el precepto Lo que es mío es mío y lo que es de usted es negociable. Si pueden obtener lo que quieren mediante juegos de poder, ¿por qué van a cooperar? (Ury, 1993: 25).

La negociación nace de la diversidad de interpretaciones de hechos, concepciones y actitudes. Es el intercambio lo que permite construir un conocimiento más contrastado.

La negociación se refiere a consensos llevados a cabo antes, durante y después del trabajo de campo para establecer ciertas condiciones y principios éticos en los que se desarrolla la producción de los datos, su análisis, discusión y socialización de los mismos. Se procura que todas las personas participantes en la investigación, acepten la investigación como un acto que 
produce conocimientos y por consiguiente tienen un potencial para mejorar las prácticas educativas o sociales. Se garantiza que la información que pueda suponer algún riesgo será confidencial (Badilla, 2016: 46).

Algunos autores se refieren a este proceso con el término de negociación (Martin, 1976; Woods, 1978; Ball, 1980; Turner, 1983; Delamont, 1984). Otros con el de consenso operativo (Pollard, 1972; Hargreaves, 1979). Eisner (1998) habla de consentimiento informado.

Más recientemente, Domínguez Montes (2015: 14) recoge las aportaciones de Latorre et al. (1996) y de Sandín (2010) sobre los procesos de negociación realizados con los participantes en el momento del acceso y de la retirada del escenario de las investigaciones.

Susinos y Parrilla (2013: 95), investigadoras en temas de educación inclusiva, reivindican igualmente el que la generación, interpretación y publicación de datos se asuma y entienda como un proceso de negociación permanente entre el investigador y los participantes. En esta línea se encuentran las aportaciones de De la Rosa (2008 y 2010), en las que se describen, argumentan y analizan críticamente los procesos de negociación realizados en la investigación con un joven con parálisis cerebral (en los que, por las dificultades de comunicación, los procesos éticos de negociación han de ser aun más rigurosos).

Lya Esther Sañudo (2015), en su artículo La ética en la investigación educativa, nos plantea que los principios éticos de la investigación implican un modo de gestión de la misma que conlleva complejos procesos de negociación entre los participantes (quienes investigan y quienes son investigados), así como con las generaciones futuras -derechos de tercera generación-.

En nuestro grupo de investigación ${ }^{2}$ hemos sido siempre muy cuidadosos con esta exigencia. Como explicaremos seguidamente, tiene fases diversas y requiere de estrategias comunicativas dialogantes.

2 Grupo de Investigación Humanidades 0365, patrocinado por la Junta de Andalucía y ubicado en el Departamento de Didáctica y Organización Escolar de la Universidad de Málaga (Director D. Miguel Ángel Santos Guerra). 


\section{Fases de la negociación}

\section{Negociación Inicial}

Sea quien sea el que ha tenido la iniciativa (investigadores o sujetos de la investigación) hay que establecer un proceso de negociación que ha de ser lo más claro, transparente, riguroso y democrático posible. No hay que negociar con la dirección sino con la comunidad. No con todos, claro está, sino con los órganos correspondientes de representación.

Y se ha de negociar todo: el método, el tiempo, las condiciones, los significados, la devolución de los informes... Somos partidarios de que esa negociación tenga un carácter formal. Procuramos que se redacte un documento y que, después de acordados sus términos, se firme por ambas partes.

La negociación del acceso no estriba solamente en entrar en una institución o grupo en el mero sentido de atravesar el umbral que separa el mundo exterior del interno, sino en atravesar diversos umbrales que indican el camino del corazón de una cultura (Woods, 1987: 39).

Existen numerosos peligros, no solo en esta fase inicial, que podrían convertir la negociación en un proceso estéril e, incluso, perjudicial.

a) Falsificarla en su misma naturaleza, a través de una apariencia de negociación que escondería una manipulación más o menos sutil. El peligro de nominalismo es grave porque al parecer que se hace negociación se provoca hipocresía y se impide un proceso auténtico. Es un engaño planificado.

b) Resistencia a la modificación por parte de quienes investigan, de tal manera que quienes van a participar en la investigación piensen que existe una actitud cerrada y hermética en quienes negocian con ellos.

c) Poner la negociación al servicio del poder, sea convocando sólo a quienes ejercen la dirección, por ejemplo, sea haciendo caso a todas sus sugerencias y rechazando las que provienen de otros sectores.

d) Ceder a las presiones de forma demagógica, a costa de la desvirtuación de los datos y de la pérdida de rigor. La edulcoración de los conflictos o desacuerdos en aras de conseguir el beneplácito de todos, constituye una forma de falsificación de la verdad. 
e) Rechazo de la crítica que se considere desfavorable, entendiendo como destructiva la que no es halagadora y constructiva la que elogia a quienes se investiga. Es preciso romper esta división en aras de otra más exigente: crítica rigurosa y crítica superficial. La primera resulta positiva aunque sea ingrata. La segunda es destructiva, aunque tenga apariencia atractiva.

Una de las causas que está en la base de estos peligros, además de las actitudes rígidas de unos y otros, es la falta de tiempo y las prisas, tanto de quienes investigan como de quienes van a participar en la investigación.

El hecho de hacer la negociación inicial no significa, pues, haberla hecho bien. Y, por supuesto, no conlleva que se utilice para favorecer la ética de los siguientes procesos ni la comprensión y mejora de la realidad.

\section{Negociación de proceso}

No se negocia de una vez para siempre. Pueden surgir situaciones imprevistas, conflictos o exigencias que obliguen a modificar los términos de la negociación inicial. Todo lo ocurrido debe plasmarse en los informes sobre el proceso.

Los ritmos pueden modificarse, pueden ampliarse o reducirse el número de informantes, pueden abrirse perspectivas que no se habían previsto. Dado el carácter emergente de las investigaciones que solemos realizar, la negociación inicial exige ser sometida a una constante revisión.

La disposición a renegociar exige un talante dialogante. Hace falta tener (y formar y cultivar) ese talante. No se nace sabiendo negociar. En las negociaciones hay intereses, principios, actitudes, estrategias, alianzas, acuerdos, conflictos, ritmos, clima, diálogo, argumentación, escucha... que reclaman un aprendizaje.

Para negociar es mejor ser inteligente que ser agresivo o complaciente (Font, 2014) y hace falta tiempo para llegar a conocer bien el contexto. Por eso resulta necesaria esta fase intermedia de la negociación.

No queremos decir que haya que estar revisando constantemente los acuerdos. Si están funcionando, no hace falta volver a ellos. 


\section{Negociación de informes}

La negociación de informes es fundamental para nosotros. Por eso nos vamos a detener en esta cuestión. No tiene mucho sentido dedicar meses a la recogida de información y no estudiar de forma intensa y enriquecedora el informe. Hablamos de negociar, no de devolver el contenido de los informes.

En tanto investigadores, debemos explicarles a los lectores el modo en que se recogieron e interpretaron los datos. Hay que proporcionarles información suficiente sobre la manera en que fue realizada la investigación para que ellos relativicen los hallazgos, es decir para que los comprendan en su contexto (Taylor y Bogdan, 1986: 180).

\section{a) Exigencias previas a la negociación de informes}

Para que la negociación sea positiva, es preciso que los que intervienen en ella tengan en cuenta algunas actitudes y algunos criterios que la conviertan en un proceso de intercambio y de aprendizaje:

- Prepararse para acudir a la negociación sabiendo qué es lo que se pretende y cómo se puede alcanzar, es decir: habiendo pensado sobre el proceso, leído los documentos, elaborado el discurso y escrito las anotaciones.

Es necesario dedicar tiempo a la preparación, aunque ello signifique quitarlo a la verdadera negociación. Las negociaciones darían mejores resultados si la gente gastara más de su limitado tiempo preparándose y menos a las verdaderas reuniones (Ury, 1993: 32).

- Compartir los códigos interpretativos para que exista una comunicación mínimamente inteligible. Cuando planteamos opiniones y hacemos análisis sin acuerdo previo sobre los códigos de significado, corremos el riesgo de no saber de lo que estamos hablando. La disparidad patente de interpretaciones es un problema que no tiene fácil solución. Se puede tender al acuerdo o al reconocimiento de las discrepancias. Creer que hay acuerdo cuando en realidad se están planteando posiciones dispares es un modo de confusión más profundo.

- Mostrar apertura. Tener un talante negociador es, precisamente, 
huir de actitudes cerradas de autoafirmación, estar abierto al diálogo, a las opiniones contrarias, a la necesaria dialéctica que exige la discusión y el debate. La apertura se opone al dogmatismo y a la intransigencia y, aunque busca el consenso, acepta el disenso.

- Desmontar los prejuicios que las informaciones previas han podido formar sobre ese tipo de experiencias, de investigaciones o de procesos. Para desmontar algunos prejuicios es preciso exigir un nivel riguroso en la argumentación, evitar las falacias y manifestar claramente las dudas.

- Argumentar con rigor, sin dar paso a tópicos interesados: falta de credibilidad a la investigación, falta de porcentajes en la recogida de opiniones, descalificaciones de las conclusiones que no interesa aceptar, formulación de excusas justificatorias...

La negociación del informe es un proceso de discusión que establecen quienes investigan y quienes son protagonistas de la acción con el fin de establecer una plataforma de discusión y de estudiar las perspectivas de cambio.

Quien investiga no realiza cambios ante cualquier tipo de opiniones si estas no se apoyan en unos argumentos convincentes o en unas evidencias claras. El hecho de que los protagonistas tengan intereses en juego, que defiendan situaciones o que mantengan presupuestos que confirman su actuación o descalifican a los contrarios, hace que quien investiga exija una rigurosa y sólida demostración antes de modificar el informe.

Cuando se realizan investigaciones y no se devuelve la información a los protagonistas se pierde una fuente importantísima de reflexión y de cambio. Si, además, los informes se publican luego, sin la participación y la anuencia de los protagonistas, se puede producir una situación inquietante de utilización de las personas.

\section{b) Características de la negociación de informes}

El proceso de negociación tiene en su planteamiento y en su desarroIlo las siguientes características:

- Subraya el carácter abierto y provisional del conocimiento. Negociar el informe supone reconocer que no existe una visión única, cerrada e indiscutible de la realidad.

- Rompe la concepción hegemónica del conocimiento que no es 
exclusiva propiedad de quienes investigan o evalúan sino de todas las personas que participan en las investigaciones.

- Democratiza la producción del conocimiento ya que todo el mundo accede a los hallazgos y puede discutir, modificar o completar lo que se ha descubierto.

- Hace posible la mejora, ya que quienes están implicados o interesados conocen lo que sucede desde un prisma diferente.

- Desmonta las actitudes reticentes, ya que la negociación hace posible la comprensión. Si la investigación es de otros, si las conclusiones no se consideran propias es más fácil que se mantengan las reticencias.

- Favorece las actitudes dialogantes o al menos ofrece una ocasión para ejercitarlas, ya que convierte el informe en una plataforma de reflexión y debate.

- Permite corregir y depurar la observación que se ha recogido, al contrastar las interpretaciones de los protagonistas con las de quienes investigan.

Por todo ello, creemos que el proceso de negociación de informes ha de estudiarse y potenciarse. No parece razonable que una exploración larga y un informe que ha supuesto un gran esfuerzo de interpretación y de síntesis den pie a una negociación apresurada de escasa intensidad y duración.

\section{c) Tipos de negociación de informes}

Puede haber distintos tipos de negociación del informe. La diversificación multiplica las dimensiones de enriquecimiento.

- En cuanto a la audiencia: Puede negociarse con todos los participantes o bien con algunos sectores. Las negociaciones parciales no deben oscurecer o debilitar la negociación de carácter global. Por eso se puede hacer una primera de carácter general, una ronda de negociaciones sectoriales y una posterior de carácter holístico.

- En cuanto a la temática: Puede haber negociación global o bien específica. También aquí planteamos la necesidad de combinar ambas fórmulas.

- En cuanto a la forma: Puede haber negociaciones escritas (mediante informes elaborados por los protagonistas o por grupos de estos), habladas (en pequeños grupos o a través de representantes), 
mixtas (entrevistas realizadas teniendo como base los informes de los diversos agentes...).

- En cuanto al tiempo: Puede haber una negociación de informes parciales o bien de un informe final único. También puede hacerse la negociación del informe final inmediatamente después de su elaboración o bien (o sucesivamente) pasado un tiempo.

\section{d) Criterios para la negociación de informes}

La negociación debe realizarse siguiendo unos criterios previamente establecidos en la fase inicial de acuerdos. Los criterios no surgen de improviso sin que antes se hayan creado las condiciones de un diálogo.

- Nadie tiene derecho al veto ni de la totalidad ni de parte del informe. Se correría el riesgo de perder toda la información. Ahora bien, es preciso garantizar el derecho de los protagonistas a expresar de forma fehaciente sus discrepancias. Por eso, en caso de no llegar a un acuerdo, es preciso dejar constancia de las diferencias de interpretación.

- Ha de existir una posibilidad de cambiar los informes, de tal modo que no se convierta la negociación en una simple justificación del proceso y de las conclusiones. Es decir, que si los protagonistas hacen ver a quienes investigan que existen distorsiones o imprecisiones, deben estos modificar sus perspectivas y cambiar la redacción.

- No se trata en la negociación de manifestar discrepancias respecto a lo que otros han manifestado con el fin de modificar las opiniones de los demás. Pueden expresarse discrepancias respecto a las opiniones ajenas, pero no se modificarán estas por ese motivo. Son los informantes quienes han de expresar sus argumentos para demostrar que no ha sido recogida fielmente su manifestación.

Uno de los problemas más complejos de la investigación tiene mucho que ver con el proceso de divulgación o diseminación del conocimiento derivado de la misma. Cuando esta se financia con fondos públicos y se refiere a un fenómeno de interés público, es obligada la difusión. Ahora bien, son los protagonistas de la acción (y no sólo quienes investigan) quienes han de determinar las circunstancias, momentos y formas de hacer esta difusión. Porque los informes son de quienes los patrocinan, de sus protagonistas y de quienes investigan, pero también, y sobre todo, de la ciudadanía en general. Así lo reconoce Barry McDonald en un conocido trabajo que, aunque ya lejano en el tiempo, mantiene todo su vigor. 
La evaluación democrática es un servicio de información a la comunidad entera sobre las características del programa educativo. El patrocinio del estudio de evaluación en sí, no concede un derecho especial sobre este servicio... El valor básico es una colectividad de ciudadanos informados y el evaluador actúa como un corredor que intercambia información entre grupos que desean conocimientos recíprocos (McDonald, 1976: 475).

\section{e) Sugerencias para facilitar un buena negociación}

La experiencia nos permite proponer algunas ideas para conseguir una negociación enriquecedora:

- Leer el informe íntegramente, no solamente algunas de sus partes (la que se refiera a la propia actuación, la que aconseje algún colega, la más llamativa o la más anecdótica).

- Destinar a la negociación un tiempo suficiente (para, incluso, leerlo más de una vez) y un momento y lugar adecuados. Cuando fallan las condiciones es fácil que se deteriore el proceso en lo que tiene de sustancial y enriquecedor.

- Distribuir copias a todos los participantes, de modo que se facilite la lectura. Cuando se llega a la negociación sin haber leído el informe se hace inútil el debate.

- Conseguir que todos puedan expresar su opinión. Si una persona o un sector acapara el tiempo y la atención, es fácil que se produzca un debate sesgado, presidido por la opinión parcial de algunas personas.

Esta negociación final estará, por supuesto, determinada por la calidad de los procesos previos de negociación.

\section{Del dicho al hecho: una investigación negociada}

Los datos del proceso de negociación que aquí se presentan han de encuadrarse en el Informe Final del Proyecto de Investigación titulado "La Participación de las Familias de Alumnos y Alumnas Inmigrantes en las Instituciones Educativas" ${ }^{3}$.

3 Proyecto aprobado y financiado por el MEC como Proyecto de I+D+I (Referencia: SEJ2007-67556/EDUC) y por la Consejería de Gobernación de la Junta de Andalucía. Ejecutado por el Grupo Consolidado de Investigación HUM 0365 de la Junta de Andalucía. 
Esta Investigación se planteó como un Estudio Multicasos en el que participaban cuatro centros de Educación Infantil y Primaria y dos Institutos de Enseñanza Secundaria de Málaga, capital y provincia.

Extraemos para este contexto los datos del proceso de negociación seguido en el caso del INSTITUTO DE ENSEÑANZA SECUNDARIA "LOS MANANTIALES", del municipio de Torremolinos (Málaga).

\section{Negociación inicial}

Nuestro primer contacto con la Directora del IES "Los Manantiales" fue telefónico. Tras comentarle el objeto de nuestra llamada y ella mostrarse motivada, convenimos un encuentro en el que acordamos invitar también al Profesor del Aula Temporal de Adaptación Lingüística (ATAL) que era quien, según su criterio, en todo lo relacionado directamente con el alumnado extranjero, conocía más los entresijos organizativos y las situaciones particulares relacionadas con dicho alumnado y sus familias.

En este encuentro, ya cara a cara, les entregamos el Documento de Negoción Inicial (Guerra y De la Rosa Moreno, 2013: 165-171) y les explicamos el propósito de la investigación que planteábamos, las razones de haber elegido su centro, la demanda de colaboración que les hacíamos, los procesos metodológicos, etc.

Posteriormente, el Documento de Negociación Inicial fue sometido al debate y a la aprobación del Consejo Escolar en una de sus sesiones ordinarias. Así mismo se les entregó y explicó personalmente a tres representantes de la AMPA.

Como era de esperar, ya desde el inicio, algunas propuestas que aparecían en dicho Documento se fueron perfilando y ajustando a la realidad del centro. Por ejemplo, respecto a las fuentes de información que el grupo de investigación planteaba, el profesor de ATAL argumentó criterios diferentes para la realización de las entrevistas a miembros de las familias de origen inmigrante, para que así representara mejor su realidad (la toma de decisiones conjunta comenzó pues desde ese momento). Tras el debate, la combinación de sus criterios (manejo de la lengua castellana, grado de facilidad en la adquisición de la misma, peculiaridades de algún grupo concreto, etc.) acabaron configurando los agrupamientos del alumnado y sus familiares para la realización de las entrevistas: chinos, latinos, del Este y marroquíes, agrupamientos que no se repiten en el resto de los centros del estudio multicaso. 
Esta fase inicial de negociación se alargó tres meses y se desarrolló en un ambiente distendido, de interés y disponibilidad que crearon un buen clima para la siguiente fase de la investigación.

\section{Negociación durante el proceso}

Ya durante la fase de recogida de la información en el centro y, con algunas familias, fuera del mismo, fuimos perfilando la propuesta inicial, principalmente, según las circunstancias e idiosincrasia del IES. Entre otras cuestiones, se fueron negociando cuestiones como:

- Los criterios para concertar las citas con las personas que se entrevistarían o se observarían en los entornos naturales.

- Se debatieron las condiciones legales y éticas de las grabaciones, lo que nos llevó a decidir cómo se debían realizar estas y el uso restrictivo que se les podría dar en los procesos de divulgación de los resultados.

- Se valoró la necesidad de contactar personalmente con el profesorado implicado durante las observaciones naturales, para asegurar su previo consentimiento informado.

- En un orden más pragmático, se ajustaron tiempos para las citas, se determinaron los espacios desde donde grabar los recreos y las entradas y salidas del centro, etc.

Progresivamente, tuvimos que ir reajustando en alguna medida también la planificación inicial sobre las fuentes de información. Algunos de los cambios que se fueron acordando fueron:

- En vez del número previsto, decidimos hacer mayor cantidad de entrevistas grupales e individuales, tanto al alumnado inmigrante y autóctono como al profesorado, otros profesionales no docentes y personal de administración y servicios (PAS).

- Sin embargo, a pesar de la mediación constante con diversas familias por parte del Profesor de ATAL y de una de las Orientadoras, así como de los diversos contactos telefónicos de las investigadoras con madres y padres para ajustarnos a sus posibilidades horarias y espaciales, de las 8 entrevistas previstas con familias de origen inmigrante, finalmente sólo lo conseguimos con 4.

- Añadimos observaciones en situaciones naturales no previstas (por ejemplo, la entrega de notas en E.S.O., con la que nos encontra- 
mos inesperadamente en uno de los días de estancia en el centro y que, in situ, con el Equipo Directivo, un profesor directamente implicado y las familias de su tutoría, acordamos llevar adelante para estar dentro del aula; sin embargo, nos fue imposible asegurar el consentimiento informado de las familias y el alumnado que observamos mientras esperaban, en los pasillos, para entrar en sus respectivas tutorías).

- Por el contrario, no llegamos a observar el funcionamiento del centro durante actividades extraordinarias, tal y como estaba acordado, por exceso de ocupaciones por parte del profesorado, precisamente por estar inmersos en la organización de la que se había previsto observar, la Semana Intercultural.

- Respecto a los documentos del centro como fuente de información, aparte de los previstos, motu proprio nos ofrecieron otros como, por ejemplo, el vídeo "El Disco de Newton", documento sobre multiculturalidad (muy pertinente al objetivo de la investigación), realizado por alumnos y alumnas de la asignatura de Medios de Comunicación y dirigido por la Profesora Dña. Cristina Fernández.

Se evidenciaba que unos y otros estábamos dispuestos a ajustar propuestas y expectativas a lo que iba surgiendo a lo largo de las diferentes fases de la investigación. Así, poco a poco, habíamos construido un Equipo de Investigación que nos comprometía en el éxito de la misma tanto a "los de dentro" como a "los de fuera".

Cuando dimos por terminadas las siguientes fases de la investigación (la de análisis e interpretación de los datos y la de redacción del informe), ya sin nuestra presencia en el centro), les entregamos el Borrador del Informe de Caso al IES "Los Manantiales". Llevamos 10 copias para que pudieran distribuirlas e intercambiarlas entre los diferentes sectores de la comunidad educativa (profesorado, personal de administración y servicios, alumnado y AMPA).

El objetivo del último encuentro sería, por tanto, recoger sus opiniones, críticas y propuestas sobre dicho Borrador del Informe de la Investigación. 


\section{Negociación del Informe}

Pasado un mes, para que dispusieran de tiempo para hacer una lectura pausada y de calidad, volvimos a encontrarnos.

En esta última reunión para la Negociación del Informe Final, a pesar de los avisos reiterados por parte del Equipo Directivo a representantes de los diversos sectores de la Comunidad Educativa (principalmente a quienes habían participado directamente en la investigación), por parte del Instituto, "solo" acudieron la Directora, el Vicedirector, el Profesor del ATAL, 2 profesoras y 4 profesores.

No hubo familias de las entrevistadas, representantes del AMPA, del alumnado ni del PAS (a pesar de que se les había entregado el Borrador del Informe, de que la Directora los había convocado y de que la Vicepresidenta de la AMPA había confirmado su asistencia). Algunos de los asistentes tampoco habían leído el informe, pero expresaron que su presencia se debía al interés que tenían por conocer un resumen de las conclusiones.

De todas las maneras, ¿deberíamos decir "solo" asistieron estas personas? Dada la insuficiente cultura de participación en las investigaciones, puede que la expresión debiera ser más satisfactoria: jestaban presentes 9 miembros del centro para el proceso de debate sobre el Informe construido!

Los miembros del Grupo de Investigación presentamos los aspectos más relevantes del Informe de Investigación, ya que había personas que no lo habían leído, y se abrió el debate sobre el mismo.

En su conjunto, el Informe fue valorado muy positivamente por sus lectores y lectoras, que quedaron gratamente impresionados por la imagen que habían visto reflejada de la vida del centro, tanto de los aspectos más positivos como de los pendientes de mejora.

De cualquier forma, asumíamos que negociábamos para buscar consensos, acuerdos, no verdades. Así que también emergieron aspectos en los que las y los presentes querían matizar, ampliar, discutir... afirmaciones que aparecían en el Borrador del Informe. Entresacamos alguna de las que después se recogieron en el Informe Final:

- La Directora advirtió sobre la opinión del alumnado que salía en el Informe en la que se expresaba que el profesorado no hacía caso a sus problemas ni a los conflictos que surgían entre ellos, cuando de hecho, manifestaba (y fue apoyada por más presentes) que era un trabajo que desarrollaban día a día, pero que quizás no era conocido por ellos o les pasaba inadvertido. 
Esta apreciación se incorporó en el Informe Final, a renglón seguido de la opinión expresada por el alumnado en las entrevistas. Así ambas perspectivas quedaban recogidas y se enriquecía la mirada sobre la realidad.

- Una de las personas que participaron en las entrevistas, comentó que se sentía incómoda al leer sus aportaciones tan mal expresadas en el Informe (como consecuencia de ser texto oral transcrito). Le comentamos que, al transcribir, modificábamos aspectos del lenguaje oral muy entorpecedores para la lectura fluida pero que entendíamos que no debíamos cambiar en lo esencial la forma de expresión. Sin embargo, entendíamos que no sería problema que, si no quería verse representada con esa forma, reelaborase en los aspectos formales una aportación propia que mencionaba en particular, manteniendo el sentido de la misma (una vez fue recibida por e-mail sustituyó a la original en el Informe Final).

- Se analizaron también algunas cuestiones que no respondían a la realidad del centro, las cuales se corrigieron en el Informe Final, como por ejemplo:

o El que en este centro no hubiera una población gitana significativa -lo que sí parecía desprenderse de una de las entrevistas-.

o La presencia a tiempo total y no parcial, desde el curso anterior, del profesor de ATAL en este centro.

o El equívoco al identificar el Aula de Convivencia con el Aula de Expulsados, cosa que habíamos malentendido tras el análisis de los documentos.

o Se nos informó también de que, el alumnado de Bachillerato que hablaba de la asignatura de Culturas Religiosas estaba en un equívoco, ya que la misma no existía en el momento de las entrevistas en esa etapa educativa (sí en la ESO recién acabada por ellos y ellas). Realmente a la asignatura a la que se referían era la de "Ayuda al Estudio".

Otros temas que despertaron el debate, se añadieron al Informe Final tal y como emergieron en ese momento.

En conclusión (y así lo recogimos en la redacción del Informe Final), la apreciación del Borrador del Informe fue positiva para todos, fundamentalmente por: 
- Su rigor: "es muy ilustrativo", "muy expositivo, las conclusiones se ve que salen de las citas de los participantes".

- Su credibilidad: "se ven datos que no sabemos, quizás por obvios, por estar demasiado dentro de la realidad", "al ser una mirada desde fuera, nos sirve de espejo para vernos desde una perspectiva más global", "es como un reportaje a pie de calle, con lo bueno, con lo malo, pero eso sí: habiendo más bueno que malo".

- Su carácter educativo, de aprendizajes para promover mejoras: "muchas cosas buenas que ni siquiera vemos, las encontramos reflejadas y podemos reconocernos en ellas. También las malas", "sería bueno dárselo a los profes cuando llegan nuevos al centro, porque les permitiría conocer un poco la realidad, por ejemplo, que el alumnado no tiene tantos prejuicios como los adultos", "todos podemos aprender al leerlo y comentarlo", "es una oportunidad para conocer el día a día, por ejemplo, acercarnos a conocer qué piensan los alumnos", "son muy interesantes las pistas que se dan en el apartado final del Informe sobre cómo algunos centros han facilitado la participación de estas familias".

Realmente, al terminar este proceso de Negociación Final, el Informe pasaba a ser un producto contrastado, reelaborado democráticamente, sentido como propio. Procesos e Informe Final podrían haber sido mejores. Lo sabíamos, pero nos sentíamos satisfechos con lo aprendido, era un principio para la mejora de la participación del alumnado inmigrante y sus familias en el centro.

Habíamos cerrado una investigación que, como había sido nuestra pretensión desde el inicio, no se había vivido como una amenaza, sino que se había convertido en una ayuda para todas las personas implicadas.

\section{Consideraciones finales}

Una investigación educativa no es la que versa sobre temas educativos, es la que realmente educa a quienes la practican. Esto supone que las reglas del juego son transparentes, que no se hacen trampas, que los principios éticos se respetan...

No puede hablarse, en propiedad, de una investigación educativa 
que no eduque a sus participantes. No se puede pensar que se están promoviendo valores educativos, si estos no se respetan, en primer lugar, en sus audiencias o en sus interlocutores. Una investigación será educativa si permite que los participantes desarrollen nuevas formas de comprensión y se les capacita para emprender caminos propios de reflexión autónoma y colaborativa sobre el sentido de la práctica educativa y sus posibilidades de mejora (Contreras, 1991).

Es precisamente ahí donde se encuentra una de las claves de la negociación: en el enlace que exige la transformación con el proceso de comprensión que ha suscitado la búsqueda. No se investiga para investigar. Se investiga para mejorar. Entre otras cosas porque la investigación no es gratuita y exige dinero, tiempo y esfuerzos que podrían dedicarse a otras cosas.

La finalidad fundamental de la investigación es la mejora de la práctica y no sólo la producción de conocimiento.

Mejora: esta sí que es una palabra honda, enigmática, infinita, competitiva, excitante, publicitaria. Al ser humano no le bastó lo bueno, lo que servía para salir al paso: quiso lo mejor... Pero lo mejor es un concepto vacío, como el de felicidad. No son más que el vaciado de la felicidad (Marina, 1995).

El debate en el que la negociación consiste se produce respecto a cuatro puntos: el rigor del proceso, la calidad de las conclusiones, la naturaleza de la mejora y la eficacia de las estrategias de cambio.

El cambio no viene marcado por las explícitas recomendaciones de quienes investigan sino por la lógica de la comprensión que establece el informe. No es, pues, quien investiga quien ha de decir a los protagonistas qué es lo que tienen que hacer en el futuro. Son estos quienes tienen el compromiso con la acción, quienes dominan las claves de la transformación, quienes tienen que aprovechar la luz producida para iluminar el camino... A lo sumo, quien investiga podrá recomendar, sugerir, proponer...

Esta posición acentúa el protagonismo de los profesionales y pone en sus manos la principal responsabilidad. No les hace dependientes de expertos ajenos a los programas o a las instituciones donde se desarrolla la acción. Puede ser que los profesionales demanden a quienes investigan una mayor concreción en las propuestas de cambio, pero creo que sería un error de concepción aceptar esa exigencia.

Muchas investigaciones se ponen en marcha por iniciativa de per- 
sonas que tienen interés por conocer diverso tipo de fenómenos. Una vez aceptada la propuesta de colaborar con quienes investigan, algunas personas colaboran ofreciendo información o siendo sujetos de una observación cuyas reglas sólo conocen quienes han diseñado el proceso de indagación. Una vez finalizada la exploración, quienes investigan, en demasiadas ocasiones, se ausentan del campo de indagación y elaboran, en la soledad de sus despachos, los informes pertinentes. Informes que, muchas veces, no llegan a conocer los informantes. Esta dinámica ha empobrecido la naturaleza de los procesos y ha generado dificultades para que nuevos investigadores accedan a los lugares que interesa explorar. Los sujetos han tenido la sensación de ser "conejillos de Indias", personas con las que se experimenta o sobre las que se investiga, pero que son ajenas por completo a la naturaleza de la investigación, al tipo de diseño, al tipo de datos que se recoge, a la interpretación que se hace de los mismos y, en definitiva, a la aplicación que se hace de ellos.

El protagonista es quien investiga, el que controla el proceso y los resultados, es quien tiene la capacidad y el tiempo y las condiciones de investigar. Este hecho profundiza el abismo que separa a los investigadores y a los prácticos. División peligrosa no sólo por las falsedades que encierra sino por la filosofía que deja traslucir. Unos piensan y otros trabajan. Unos investigan y otros aplican el resultado de esos estudios.

La jerarquía entre académicos y enseñantes se traduce en una jerarquía entre la investigación y la práctica, de tal modo que se restablece una conexión unilateral entre la primera y la segunda. Se concibe la investigación como una fuente de influencia y la práctica como la receptora de dicha influencia (Contreras, 1991: 62).

La investigación naturalista no concluye con la redacción del informe final. Es precisamente el informe un punto de partida para avivar la reflexión y promover el cambio y la mejora.

\section{Referencias bibliográficas}

Ball, S. J. (1980). Inicial encounters in the classroom and the process of the establishment. En Woods, P. (Comp.), Pupil strategies. London: Croom Helm.

Badilla, L. (2016). Fundamentos del paradigma cualitativo en la investigación educativa. Revista de Ciencias del Ejercicio y la Salud, 4 (1), $42-51$.

Contreras, J. (1991). El sentido educativo de la investigación. Cuadernos de Pedagogía. $196,61-67$. 
La negociación, piedra angular de las investigaciones Miguel Ángel Santos Guerra y Lourdes De la Rosa Moreno

Delamont, S. (1984). La interacción didáctica. Madrid: Cincel.

De La Rosa Moreno, L. (2008). Historia de Vida de Ángel. Parálisis cerebral, normalidad y comunicación. Madrid: La Muralla.

De La Rosa Moreno, L. (2010). ¿Investigamos juntos? Personas con discapacidad, historias de vida y emancipación. Revista de Educación Inclusiva, 3 (3), 11-22.

Domínguez Montes, J. A. (2015). De la investigación científica a la investigación cualitativa en educación. Fundamentación. Revista Supervisión 21, 36, 11-22.

Eisner, E. W. (1998). El ojo ilustrado. Indagación cualitativa y mejora de la práctica educativa. Barcelona: Paidós.

Font Barrot, A. (2014): Las 12 leyes de la negociación. Conecta. Barcelona.

Hargreaves. D. H. (1979). Las relaciones interpersonales en educación. Madrid: Narcea. Marina, J. A. (1995). Ética para náufragos. Barcelona: Crítica.

Martin, W. B. W. (1976). The negotiated Orden of the School. Toronto: McMillan.

McDonald, B. (1976). La evaluación y el control democrático de la educación. En Gimeno Sacristán, J. y Pérez Gómez, A. I. (1983), La enseñanza, su teoría y su práctica. Madrid: Akal.

Pollard, A. (1979). Negotiating deviance and "getting done" in primary school. En Barton, L. y Meighan, R. (Comp.), School, Pupils and Deviance. Driffield: Nafferton.

Sandín, M. P. (2010). Investigación cualitativa en educación. Fundamentos y tradiciones. Madrid: McGraw-Hill Interamericana de España.

Santos, M. A. (1990). Hacer visible lo cotidiano. Teoría y práctica de la evaluación cualitativa de Centros Escolares. Madrid: Akal.

Santos Guerra, M. Á. y De La Rosa Moreno, L. (2013). La escuela sin muros. La participación de las familias inmigrantes en las instituciones educativas. Málaga: Edit. Aljibe.

Sañudo, L. E. (2015). La ética en la investigación educativa. Hallazgos - Producción de Conocimiento, 3(6), 83-98. DOI: http://dx.doi.org/10.15332/s1794-3841.2006.0006.05

Susinos, T. y Parrilla, Ma Á. (2013). Investigación inclusiva en tiempos difíciles. Certezas provisionales y debates pendientes. Revista Iberoamericana sobre Calidad, Eficacia y Cambio en Educación, 11, 2, 87-98.

Taylor, S.J. y Bogdan, R. (1986). Introducción a los métodos cualitativos de investigación. Barcelona: Paidós Studio.

Turner, G. (1983). The Social World of the Comprehensive School. London: Croom Helm.

Ury, W. (1993). De la negociación al acuerdo. Claves para superar cualquier negociación. Bogotá: Parramón.

Woods, P. (1978). Negotiating the demands of schoolwork. Journal of Curriculum Studies, 10 (4), 309-327.

Woods, P. (1987). La escuela por dentro. La etnografía en la investigación educativa. Barcelona: Paidós/MEC. 
